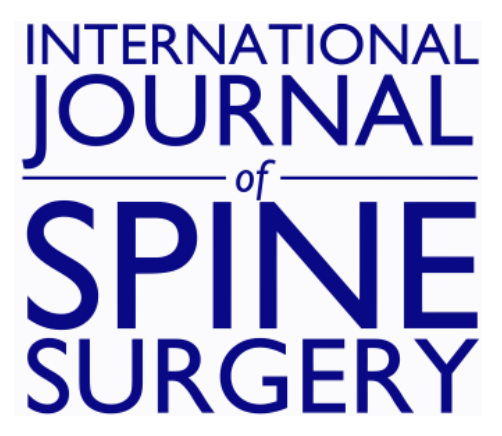

\title{
Skipping Pedicle Screw Insertion Into Infected Vertebra is a Risk Factor for Revision Surgery for Pyogenic Spondylitis in the Lower Thoracic and Lumbar Spine
}

KOSEI NAGATA, TAKESHI ANDO, KATSUYUKI SASAKI and DAIKI URAYAMA

Int J Spine Surg 2020, 14 (6) 989-995

doi: https://doi.org/10.14444/7148

http://ijssurgery.com/content/14/6/989

This information is current as of April 26, 2023.

Email Alerts Receive free email-alerts when new articles cite this article. Sign up at:

http://ijssurgery.com/alerts

The International Journal of Spine Surgery

2397 Waterbury Circle, Suite 1,

Aurora, IL 60504, Phone: +1-630-375-1432 


\title{
Skipping Pedicle Screw Insertion Into Infected Vertebra is a Risk Factor for Revision Surgery for Pyogenic Spondylitis in the Lower Thoracic and Lumbar Spine
}

\author{
KOSEI NAGATA, MD, ${ }^{1}$ TAKESHI ANDO, MD, ${ }^{2}$ KATSUYUKI SASAKI, MD, ${ }^{2}$ DAIKI URAYAMA, $\mathrm{MD}^{2}$ \\ ${ }^{1}$ Department of Orthopaedic Surgery and Spinal Surgery, The University of Tokyo Hospital, Tokyo, Japan, ${ }^{2}$ Department of Orthopedic Surgery, Hitachi General \\ Hospital, Ibaraki, Japan
}

\begin{abstract}
Background: Surgical intervention for pyogenic spondylitis is indicated when conservative treatment fails and biomechanical instability persists. Whether to insert pedicle screws into all vertebrae, including the most erosive vertebrae, or whether to skip 1 vertebra in pedicle screw insertion remains controversial.

Methods: A single-institution retrospective cohort study was conducted in consecutive patients with pyogenic spondylitis in the lower thoracic and lumbar spine (T9-S1) between January 2008 and December 2016. The patients were treated with interbody fusion plus posterior stabilization using pedicle screws and were divided into 2 groups as follows: (1) patients in whom 1 vertebra, usually the most erosive, was skipped in pedicle screw insertion (Group Skipping) and (2) pedicle screw insertion into all vertebrae (Group All). Patients' operation data were evaluated, and clinical outcomes were compared between the 2 groups. There were no significant differences between the 2 groups in terms of age, sex, past histories, blood loss, operation time, the presence of abscesses, or operative approach.

Results: The length of fixation was greater by 1 vertebral level in the Group Skipping than in the Group All, and the rate of revision surgery for pseudarthrosis was higher in the Group Skipping than in the Group All $(P=.02)$. There was no statistically significant difference between the 2 groups in terms of the mean segmental lordotic angle or Barthel Index.

Conclusions: Skipping pedicle screw insertion for pyogenic spondylitis in posterior fixation led to an increased number of fixed vertebrae and may be a risk factor for revision surgery for pseudarthrosis.

Level of Evidence: 4.

Clinical Relevance: The insertion of short pedicle screws at the infected vertebra can prevent early treatment failure and increase the biomechanical stability of construct.

Complications

Keywords: pseudarthrosis, posterior fixation, mechanical instability
\end{abstract}

\section{INTRODUCTION}

Surgical intervention for pyogenic spondylitis in the lower thoracic and lumbar spine is indicated when conservative treatment fails, progressive vertebral body destruction or neurologic deficit develops, or epidural or psoas abscesses are present. ${ }^{1-3}$ The radical debridement of infected tissue followed by interbody fusion may be the best method to control infection at the surgical site and promote definitive healing, ${ }^{4}$ although there is no scientific consensus on the role of posterior instrumentation in vertebral osteomyelitis. ${ }^{5,6}$ Therefore, it is controversial as to whether insertion of pedicle screws into infected vertebrae should be undertaken when vertebral body erosion is severe.
Inserting pedicle screws into an infected vertebral body is associated with a significant risk of bacterial spread and biofilm formation, ${ }^{7-9}$ which in turn are associated with the need for debridement reoperations. In contrast, skipping pedicle screw insertion leads to longer fixation levels and decreased mechanical stability. ${ }^{10,11}$ Additionally, in the treatment of thoracolumbar burst fractures, which are similar to pyogenic spondylitis in terms of biomechanical instability, the insertion of pedicle screws at the fracture site prevents early treatment failure and increases the biomechanical stability of construct. ${ }^{10,12}$ To the best of our knowledge, there have been no reports comparing the insertion of pedicle screws into all vertebrae and the skipping of 1 vertebra in pedicle screws insertion in patients with 
pyogenic spondylitis in the lower thoracic and lumbar spine. The purpose of this study was to compare the reoperation rate due to debridement or revision between the skipping pedicle screw insertion and the insertion of pedicle screws in all vertebrae in patients with pyogenic spondylitis.

\section{MATERIALS AND METHODS}

After institutional review board approval, we retrospectively reviewed medical records of consecutive patients with pyogenic spondylitis in the lower thoracic and lumbar spine (T9-S1) at Hitachi General Hospital between January 2008 and December 2016. They were surgically treated with interbody fusion plus posterior stabilization using pedicle screws (Expedium, DePuy Synthes, West Chester, PA, or SOLERA5.5/6.0, Medtronic, Minneapolis, MN). Conservative treatment had failed in all patients. All patients were Griffith classification ${ }^{13}$ stage 2 and exhibited moderate or severe destruction of endplate (Grade 2 or 3), which was detected on computed tomography scans and plain radiographs. ${ }^{14}$ Patients suffering from surgical site infection (past history of spine surgery) were not included in this study.

A single-institution retrospective cohort study was performed after dividing the patient population into 2 groups as follows: (1) patients who underwent skipping pedicle screw insertion into the most infected vertebra (Group Skipping) and (2) patients who underwent pedicle screw insertion into all vertebrae (Group All). Operative methods included interbody fusion via the posterior or lateral retroperitoneal (anterior) surgical approach. ${ }^{4}$ After disc space debridement, either iliac bone autograft or titanium mesh cages (Pyramesh, Medtronic, Minneapolis, MN) was used for anterior column reconstruction. Single- or 2-stage surgery was performed depending upon the patient's general condition. Pedicle screw fixation for segment instrumentation was basically 1 level above and 1 level below the most destroyed vertebra and was determined according to the bone quality and findings of the intraoperative efficiency of the screws.

Age, gender, past histories calculated by Charlson Comorbidity Index (CCI) ${ }^{15}$ level of infection involvement, and the expansion of abscess were evaluated. The presence of epidural or psoas abscesses was evaluated using magnetic resonance imaging. Moreover, operative methods, blood loss, operation time, and the number of vertebrae into which pedicle screws were inserted were evaluated.

The loss of segmental lordotic angle was measured as the angle of a perpendicular line from the upper and lower endplates of the involved vertebrae comparing the preoperative and the latest follow-up radiographs. ${ }^{16}$ In revision cases, this angle was measured as the angle just before the revision surgery as the latest follow up.

The minimum follow up was 11 months except for fatal cases. Intravenous antibiotics were administered for at least 6 weeks after operation or until C-reactive protein levels returned to normal, followed by oral antibiotics for 6 weeks. Reoperation patterns were classified into early debridement, characterized by fever or elevated C-reactive protein levels, and late pseudarthrosis, diagnosed by radiological instability and nonunion without bone erosion. Both preoperative and postoperative neurological statuses were recorded by board-certified spine surgeons. Patients' basic activities of daily living were evaluated by Barthel Index. ${ }^{17}$

Statistical significance of associations between categorical variables was assessed using the Fisher exact test (with continuity correction for $2 \times 2$ tables). Continuous variables were compared using unpaired $t$ tests, and the level of statistical significance was set at $P<.05$. Data were managed using the SAS version 9.4 (Cary, NC).

\section{RESULTS}

In total, 36 patients were included in the study; 13 patients were assigned to the Group Skipping, and 23 patients were assigned to the Group All. Mean follow-up length was 24 (11-48) months. In the Group Skipping, there were 8 males and 5 females, with age at admission ranging from 40-83 years (mean $=70$ ). In the Group All, there were 16 males and 7 females, with age at admission ranging from 40-83 years (mean $=73$ ). Mean CCI was 2.7 in the Group Skipping and 2.5 in the Group All, without statistically significant differences. There was no trend in the presence of psoas abscesses, epidural abscess, neurological deterioration, or endplate destruction between the 2 groups (Table 1). Staphylococcus aureus was the most common infectious agent (Group Skipping, $\mathrm{n}=4$; Group All, $\mathrm{n}=9$ ).

In total, 5 patients in the Group Skipping and 7 patients in the Group All underwent 2-stage surgery (Table 2). The reasons for treating these patients 
Table 1. Characteristics of 36 patients with pyogenic spondylitis.

\begin{tabular}{lccc}
\hline & $\begin{array}{c}\text { Group Skipping } \\
(\mathbf{n}=\mathbf{1 3})\end{array}$ & $\begin{array}{c}\text { Group All } \\
(\mathbf{n}=\mathbf{2 3})\end{array}$ & $\begin{array}{c}\boldsymbol{P} \\
\text { Value }\end{array}$ \\
\hline Age, mean, y & 70 & 73 & $.28^{*}$ \\
Male/female & $8 / 5$ & $16 / 7$ & .72 \\
CCI & 2.7 & 2.5 & $.82^{*}$ \\
Multilevel discitis & 1 & 3 & 1.0 \\
Psoas abscess & 4 & 6 & 1.0 \\
Epidural abscess & 2 & 7 & .55 \\
Neurological problem & 2 & 2 & .95 \\
Endplate destruction (grade 2/3) & $5 / 8$ & $6 / 17$ & .48 \\
\hline
\end{tabular}

Abbreviation: CCI, Charlson Comorbidity Index.

*Analyzed by $t$ test, and others were assessed using the Fisher exact test.

with 2-stage anterior debridement and posterior fusion were as follows: (1) their general condition was rather poor to undergo surgery lasting for more than 2 hours in the first operation $(n=9)$, and (2) the psoas abscesses were large and continuous and required drainage for at least 1 week $(\mathrm{n}=3)$. Interbody fusion surgeries were performed via a retroperitoneal approach in all patients. There were no statistically significant differences between groups in terms of the mean number of posteriorly fixed vertebrae (4.8 in Group Skipping versus 3.8 in Group All; $P=.02)$. A titanium mesh cage was used for 9 patients in the Group Skipping and for 13 patients in the Group All. There was no significant difference in terms of mean estimated blood loss (1696 mL versus $1469 \mathrm{~mL}, P=.71$ ) and operation time of posterior part (199 minutes versus 195 minutes, $P=.51$ ) between the 2 groups.

Table 3 shows the information of the 13 patients in the Group Skip with the level of the most infected vertebra and outcome. The rate of revision surgery required due to pseudarthrosis was higher in the Group Skipping than in the Group All $(\mathrm{n}=5$ versus $\mathrm{n}=1$, respectively; $P=.02$; Table 4 ). These cases required surgical intervention, including reconstruction and fusion with longer instrumentation at more than 6 months after the first surgery. Representative cases were shown in Figure 1 and Figure 2. However, there was no difference in the rate of debridement caused by the recurrence of infection between the 2 groups $(\mathrm{n}=2$ in Group Skipping versus $\mathrm{n}=4$ in Group All; $P=1.0$ ). There was no statistical difference between the 2 groups in terms of the change of segmental lordotic angle from the angle on admission of the most infected site $\left(5.7^{\circ}\right.$ in Group Skipping versus $5.4^{\circ}$ in Group All; $P=.85$ ). In total, 6 patients in the Group Skipping and 16 patients in the Group All regained ambulatory ability, without statistically significant differences
Table 2. Surgical data.

\begin{tabular}{lccc}
\hline & $\begin{array}{c}\text { Group Skipping } \\
(\mathbf{n}=\mathbf{1 3})\end{array}$ & $\begin{array}{c}\text { Group All } \\
(\mathbf{n}=\mathbf{2 3})\end{array}$ & $\begin{array}{c}\boldsymbol{P} \\
\text { Value }\end{array}$ \\
\hline 2-stage surgery & 5 & 7 & .72 \\
Length of fixation, no. of vertebra & 4.8 & 3.8 & $.02 *$ \\
Mesh cage/strut & $9 / 4$ & $13 / 10$ & .50 \\
Retroperitoneal & 5 & 10 & 1.0 \\
Operation time, min & 199 & 195 & .77 \\
Estimated blood loss, mL & 1469 & 1697 & .71 \\
\hline
\end{tabular}

*Analyzed using the Fisher exact test, and others were assessed by $t$ test.

between the 2 groups $(P=.29)$. In-hospital mortality was observed in 1 patient in the Group Skipping and 1 patient in the Group All. There was no statistical difference between the 2 groups in terms of the change of Barthel Index (Table 5).

\section{DISCUSSION}

This study investigated the association between pedicle screws insertion pattern and the risk for revision surgery caused by pseudarthrosis. Our data demonstrated that the fixation length became longer and the rate of revision surgery performed for pseudarthrosis increased when pedicle screw insertion into the most infected vertebrae was skipped. The loss of segmental lordotic angle was approximately $5^{\circ}$ from the mean angle during 24 months of follow up. Finally, $22(61 \%)$ of the 36 patients regained ambulatory ability, and the mortality rate was $5.6 \%$ in our series. In cases of skipping pedicle screw insertion, the pseudarthrosis may be associated with longer lever arm, poor compression power, but not with the recurrence of infection at the site of surgery.

Previous reports have revealed that pseudarthrosis was observed in approximately $10 \%$ of patients after posterior fixation via interbody fusion for pyogenic spondylitis. ${ }^{18,19}$ Long posterior fixation with short fusion in the treatment of pyogenic spondylitis of the thoracic and lumbar spine has been reported to result in a $3.0^{\circ}$ correction loss and $8 \%$ screw backout. ${ }^{20}$ Pseudarthrosis was observed in $12 \%$ of patients after posterior instrumentation and anterior column reconstruction in thoracic and lumbar spine via single posterior approach. ${ }^{21}$ D'Aliberti et $\mathrm{al}^{4}$ have argued that an anterior standalone approach is feasible and have reported pseudarthrosis in $2.5 \%$ of cases; however, this report included cervical cases during the acute phase of pyogenic spondylitis. Patients with multiple medical comorbidities often developed complica- 
Table 3. The 13 patients in the Group Skipping showing the level of the most infected sites and outcome.

\begin{tabular}{|c|c|c|c|c|}
\hline Age & Sex & $\begin{array}{l}\text { Iost Infected } \\
\text { Level }\end{array}$ & Surgical Method & Outcome \\
\hline 76 & $\mathrm{~F}$ & L4-5 & L3-S1 anterior and posterior fixation & \\
\hline 80 & $\mathrm{~F}$ & L1-2-3 & T12-L4 2-staged anterior and posterior fixation & \\
\hline 57 & M & L4-5 & L3-iliac 2-staged debridement and posterior fixation & \\
\hline 61 & M & $\mathrm{L} 1-2$ & T12-L3 posterior fixation & \\
\hline 74 & M & $\mathrm{T} 12-\mathrm{L} 1$ & T10-L2 posterior fixation & \\
\hline 83 & M & L5-S & L3-iliac posterior fixation & \\
\hline 66 & $\mathrm{M}$ & L4-5 & L3-S1 anterior and posterior fixation & Reoperation by pseudoarthrosis \\
\hline 75 & M & L3-4 & L2-4 2-staged anterior and posterior fixation & Reoperation by pseudoarthrosis \\
\hline 63 & $\mathrm{~F}$ & $\mathrm{~T} 11-12$ & T9-L3 2-staged anterior and posterior fixation & T4-iliac fixation by pseudoarthrosis \\
\hline 76 & $\mathrm{~F}$ & $\mathrm{~T} 10-11$ & T8-L1 posterior fixation & Reoperation by pseudoarthrosis \\
\hline 61 & M & L2-3 & L1-4 posterior fixation & Reoperation by debridement \\
\hline 71 & $\mathrm{~F}$ & L4-5 & $\begin{array}{l}\text { L2-iliac 2-staged bilateral debridement and anterior/ } \\
\text { posterior fixation }\end{array}$ & Died $50 \mathrm{~d}$ after the first surgery \\
\hline 61 & M & $\mathrm{L} 1-2$ & T12-L3 posterior fixation & $\begin{array}{l}\text { Reoperation by debridement and by } \\
\text { pseudoarthrosis }\end{array}$ \\
\hline
\end{tabular}

tions, including the relapse of infection and pseudarthrosis, ${ }^{20}$ and the risk of pseudarthrosis may be higher than the reported figures during the late phase of pyogenic spondylitis.

The cause of pseudarthrosis and the requirement of revision surgery for bone erosion in pyogenic spondylitis were similar to those for other pathologies. Some reports pertaining to adult spinal deformity have indicated several risk factors for postoperative pseudarthrosis, including medical comorbidities $^{23}$ and severe preoperative sagittal imbalance. ${ }^{22,23}$ In this study, there was no difference in terms of medical comorbidities, as measured by CCI, between the 2 groups. Although severe preoperative sagittal imbalance has been reported in a revision case series, correcting such an imbalance may by extremely difficult in elderly people because of the frailty of their bones. ${ }^{24}$ Our data revealed that longer fusion time caused by skipping pedicle screw insertion was a risk factor for pseudarthrosis in patients with pyogenic spondylitis. We presumed that the stress concentrated at the fused level or adjacent segment would be greater after fusion surgery in patients undergoing skipping pedicle screw insertion than in patients undergoing the insertion of screws all vertebrae; this can be

Table 4. Summary of clinical outcomes.

\begin{tabular}{lccc}
\hline & $\begin{array}{c}\text { Group Skipping } \\
(\mathbf{n}=\mathbf{1 3})\end{array}$ & $\begin{array}{c}\text { Group All } \\
(\mathbf{n}=\mathbf{2 3})\end{array}$ & $\begin{array}{c}\boldsymbol{P} \\
\text { Value }\end{array}$ \\
\hline Reoperation by pseudoarthrosis & 5 & 1 & .02 \\
Reoperation by debridement & 2 & 4 & 1.0 \\
Loss of segmental kyphosis, $^{\circ}$ & 5.7 & 5.4 & $.85^{*}$ \\
Ambulatory ability & 6 & 16 & .29 \\
Mortality & 1 & 1 & 1.0
\end{tabular}

*Analyzed by $t$ test, and others were assessed using the Fisher exact test. attributed to longer lever arm in cases of skipping pedicle screw insertion, as posited by the theory of diffuse idiopathic skeletal hyperostosis (DISH) ${ }^{25}$; however, there were no DISH patients included in our case series.

Various methods have been proposed to reduce the risk of pseudarthrosis associated with posterior fixation. The use of a titanium mesh cage has been reported to offer potential to reduce pseudarthrosis. ${ }^{26}$ Interbody fusion at more than 2 levels in lower lumbar spine $^{27}$ or long segment posterior fusion ${ }^{28}$ may reduce the risk of revision surgery. In cases presenting with a vertebral body defect, such as osteotomy, the 4-rod technique offers the potential for reducing pseudarthrosis. ${ }^{29}$ However, the risk of surgical site infection may increase due to the increased number of implants and prolonged operation time. Because vertebral inflammation predominantly erodes endplates of the vertebral bodies and rarely the pedicle, ${ }^{7,14} 30-\mathrm{mm}$ pedicle screws were inserted into our patients regardless of severe vertebral body destruction.

Several limitations of this study should be acknowledged. First, the sample size was small to conduct a multivariable analysis because of the rarity and severity of pyogenic spondylitis requiring posterior fixation. Second, although all our procedures included debridement and interbody fusion,

Table 5. Barthel Index change in the 2 groups.

\begin{tabular}{lccc}
\hline & $\begin{array}{c}\text { Group Skipping } \\
(\mathbf{n}=\mathbf{1 3})\end{array}$ & $\begin{array}{c}\text { Group All } \\
(\mathbf{n}=\mathbf{2 3})\end{array}$ & $\boldsymbol{P}$ Value \\
\hline Preoperation & 23 & 23 & .69 \\
Postoperation & 77 & 61 & .89 \\
Final follow-up & 63 & 61 & .76 \\
\hline
\end{tabular}




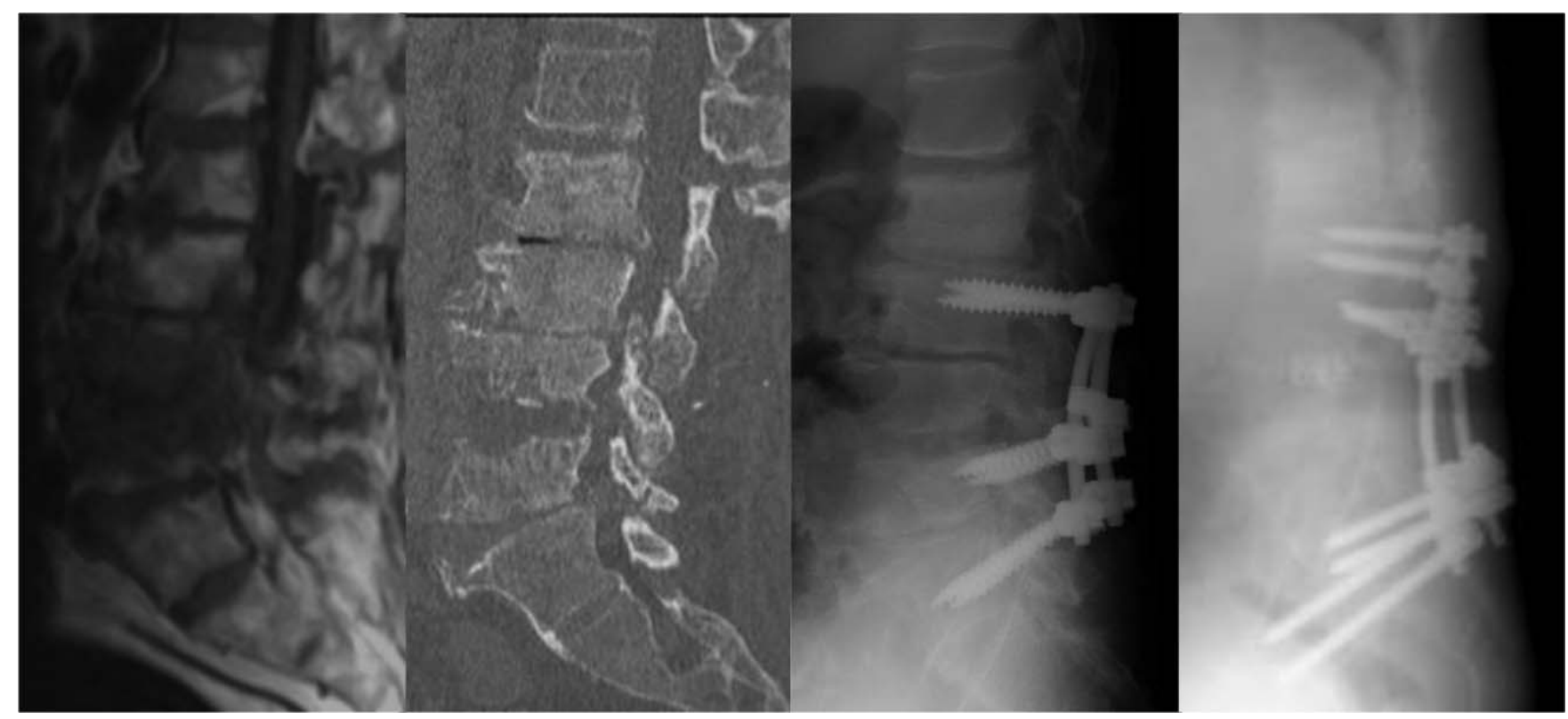

Figure 1. Images of a representative case of Group Skipping. T1-weited magnetic resonance imaging, computed tomography, postoperative $\mathrm{x}$ ray, and follow-up $\mathrm{x}$ ray. A 75-year-old male patient with L3-4 pyogenic spondylitis undergoing finally L2-iliac fixation 6 months after 2-staged L2-L5 fixation with skipping L3.

single- or 2-stage surgery for posterior instrumentation or approach for interbody fusion (retroperitoneal or posterior) was approved in the same way. Third, pelivac incisence minus lumbar lordosis mismatch or sagittal vertical axis was not discussed in this study because 12 of the 36 patients lost ambulatory ability, and they could not be evaluated in standing position. Fourth, the possibility of the relapse of pyogenic spondylitis could not be excluded during the diagnosis of pseudarthrosis, although all 6 patients who required revision surgery did not show abnormal laboratory findings before the revision surgery or abscess formation during the surgery.

\section{CONCLUSIONS}

In summary, a retrospective cohort study was performed in patients with lower thoracic and lumbar pyogenic spondylitis, who had lost their ambulatory ability due to failure in conservative treatment. Our findings indicate that skipping

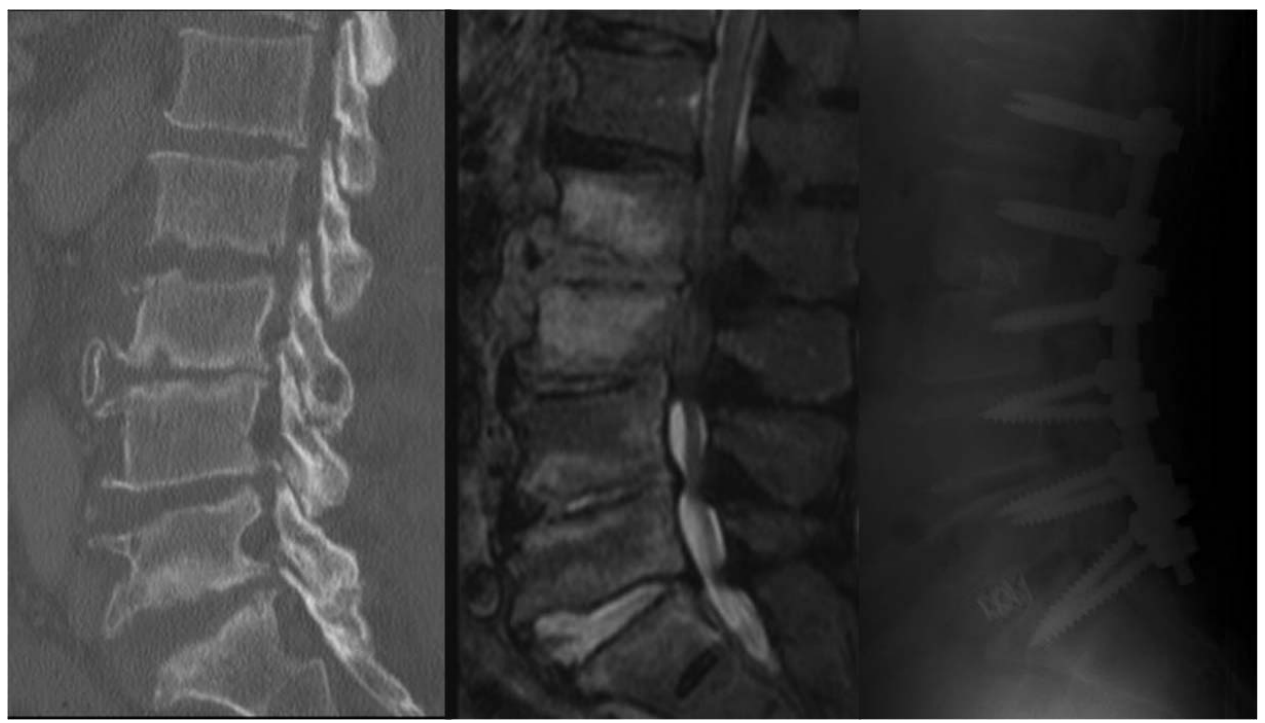

Figure 2. Images of a representative case of Group All. T2-weited magnetic resonance imaging, computed tomography, postoperative $\mathrm{x}$ ray, and follow-up $\mathrm{x}$ ray. An 80-year-old male patient with L2-3 pyogenic spondylitis with abscess undergoing 2-staged L1-S fixation with interbody fusion. 
pedicle screw insertion requires longer fixation and may be associated with the risk of revision surgery for pseudarthrosis.

\section{REFERENCES}

1. Lin TY, Tsai TT, Lu ML, et al. Comparison of two-stage open versus percutaneous pedicle screw fixation in treating pyogenic spondylodiscitis. BMC Musculoskelet Disord. 2014;15:1-8. doi:10.1186/1471-2474-15-443

2. Hempelmann RG, Mater E, Schön R. Septic hematogenous lumbar spondylodiscitis in elderly patients with multiple risk factors: Efficacy of posterior stabilization and interbody fusion with iliac crest bone graft. Eur Spine J. 2010;19(10):1720-1727. doi:10.1007/s00586-010-1448-0

3. Dimar JR, Carreon LY, Glassman SD, et al. Treatment of pyogenic vertebral osteomyelitis with anterior debridement and fusion followed by delayed posterior spinal fusion. Spine (Phila Pa 1976). 2004;29(3):326-332. doi:10.1097/01.BRS.0000109410. 46538.74

4. D'Aliberti G, Talamonti G, Villa F, Debernardi A. The anterior stand-alone approach (ASAA) during the acute phase of spondylodiscitis: results in 40 consecutively treated patients. Eur Spine J. 2012;21(suppl 1):S75-82. doi:10.1007/s00586-0122238-7

5. Hee HT, Majd ME, Holt RT, Pienkowski D. Better treatment of vertebral osteomyelitis using posterior stabilization and titanium mesh cages. J Spinal Disord Tech. 2002;15(2):149-156. doi:10.1097/00024720-200204000-00010

6. Valancius K, Hansen ES, Hoy K, et al. Failure modes in conservative and surgical management of infectious spondylodiscitis. Eur Spine J. 2013;22(8):1837-1844. doi:10.1007/s00586012-2614-3

7. Zimmerli W. Clinical practice. Vertebral osteomyelitis. $N$ Engl J Med. 2010;362(11):1022-1029. doi:10.1056/NEJMcp09 10753

8. Korovessis $\mathrm{P}$, Repantis $\mathrm{T}$, Iliopoulos $\mathrm{P}$, et al. Beneficial influence of titanium mesh cage on infection healing and spinal reconstruction in hematogenous septic spondylitis: a retrospective analysis of surgical outcome of twenty-five consecutive cases and review of literature. Spine (Phila Pa 1976). 2008;33(21):E759-67. doi:10.1097/BRS.0b013e318187875e

9. Chen WH, Jiang LS, Dai LY. Surgical treatment of pyogenic vertebral osteomyelitis with spinal instrumentation. Eur Spine J. 2007;16(9):1307-1316. doi:10.1007/s00586-0060251-4

10. Liao J-C, Chen W-P, Wang H. Treatment of thoracolumbar burst fractures by short-segment pedicle screw fixation using a combination of two additional pedicle screws and vertebroplasty at the level of the fracture: a finite element analysis. BMC Musculoskelet Disord. 2017;18(1):262. doi:10. 1186/s12891-017-1623-0

11. Kanna RM, Shetty AP, Rajasekaran S. Posterior fixation including the fractured vertebra for severe unstable thoracolumbar fractures. Spine J. 2015;15(2):256-264. doi:10. 1016/j.spinee.2014.09.004

12. Uzumcugil O, Dogan A, Yetis M, et al. Results of 'two above-one below approach' with intermediate screws at the fracture site in the surgical treatment of thoracolumbar burst fractures. Kobe J Med Sci. 2010;56(2):E67-78.
13. Griffiths HE, Jones DM. Pyogenic infection of the spine. A review of twenty-eight cases. $J$ Bone Joint Surg $[\mathrm{Br}]$. 1971;53(3):383-391.

14. Pee YH, Park JD, Choi Y-G, Lee S-H. Anterior debridement and fusion followed by posterior pedicle screw fixation in pyogenic spondylodiscitis: autologous iliac bone strut versus cage. J Neurosurg Spine. 2008;8(5):405-412. doi:10. 3171/SPI/2008/8/5/405

15. Charlson ME, Pompei P, Ales KL, MacKenzie CR. A new method of classifying prognostic comorbidity in longitudinal studies: development and validation. $J$ Chronic Dis. 1987;40(5):373-383.

16. Ha KY, Kim YH, Seo JY, Bae SH. Percutaneous posterior instrumentation followed by direct lateral interbody fusion for lumbar infectious spondylitis. J Spinal Disord Tech. 2013;26(3):95-100. doi:10.1097/BSD.0b013e31826eaf56

17. Mshoney FI, Barthel DW. Functional evaluation: the Barthel Index. Md State Med J. 1965;14:61-65.

18. Fayazi AH, Ludwig SC, Dabbah M, et al. Preliminary results of staged anterior debridement and reconstruction using titanium mesh cages in the treatment of thoracolumbar vertebral osteomyelitis. Spine J. 2004;4(4):388-395. doi:10. 1016/j.spinee.2004.01.004

19. Schomacher M, Finger T, Koeppen D, et al. Application of titanium and polyetheretherketone cages in the treatment of pyogenic spondylodiscitis. Clin Neurol Neurosurg. 2014;127:6570. doi:10.1016/j.clineuro.2014.09.027

20. Lin CP, Ma HL, Wang ST, et al. Surgical results of long posterior fixation with short fusion in the treatment of pyogenic spondylodiscitis of the thoracic and lumbar spine: a retrospective study. Spine (Phila Pa 1976). 2012;37(25):E1572-1579. doi:10.1097/BRS.0b013e31827399b8

21. Gorensek M, Kosak R, Travnik L, Vengust R. Posterior instrumentation, anterior column reconstruction with single posterior approach for treatment of pyogenic osteomyelitis of thoracic and lumbar spine. Eur Spine J. 2013;22(3):633-641. doi:10.1007/s00586-012-2487-5

22. Inoue S, Khashan M, Fujimori T, Berven SH. Analysis of mechanical failure associated with reoperation in spinal fusion to the sacrum in adult spinal deformity. J Orthop Sci. 2015;20(4):609-616. doi:10.1007/s00776-015-0729-1

23. Shigematsu H, Koizumi M, Iida J, et al. Floating spine after pedicle subtraction osteotomy for post-traumatic kyphosis. Eur Spine J. 2014;23(suppl 2):278-284. doi:10.1007/s00586014-3298-7

24. Yagi $M$, King AB, Boachie-Adjei O. Incidence, risk factors, and natural course of proximal junctional kyphosis: surgical outcomes review of adult idiopathic scoliosis. minimum 5 years of follow-up. Spine (Phila Pa 1976). 2012;37(17):14791489. doi:10.1097/BRS.0b013e31824e4888

25. Otsuki B, Fujibayashi S, Takemoto M, et al. Diffuse idiopathic skeletal hyperostosis (DISH) is a risk factor for further surgery in short-segment lumbar interbody fusion. Eur Spine J. 2015;24(11):2514-2519. doi:10.1007/s00586-014-3603-5

26. Korovessis P, Vardakastanis K, Fennema P, Syrimbeis $\mathrm{V}$. Mesh cage for treatment of hematogenous spondylitis and spondylodiskitis. How safe and successful is its use in acute and chronic complicated cases? A systematic review of literature over a decade. Eur J Orthop Surg Traumatol. 2016;26(7):753761. doi:10.1007/s00590-016-1803-x

27. Disch AC, Schmoelz W, Matziolis G, et al. Higher risk of 
adjacent segment degeneration after floating fusions: long-term outcome after low lumbar spine fusions. J Spinal Disord Tech. 2008;21(2):79-85. doi:10.1097/BSD.0b013e3180577259

28. Yunoki M, Suzuki K, Uneda A, et al. The importance of recognizing diffuse idiopathic skeletal hyperostosis for neurosurgeons: a review. Neurol Med Chir (Tokyo). 2016;56(8):510515. doi:10.2176/nmc.ra.2016-0013

29. Gupta S, Eksi MS, Ames CP, et al. A novel 4-rod technique offers potential to reduce rod breakage and pseudarthrosis in pedicle subtraction osteotomies for adult spinal seformity correction. Oper Neurosurg (Hagerstown). 2018;14(4):449-456. doi:10.1093/ons/opx151

Disclosures and COI: The manuscript submitted does not contain information about medical device(s)/drug(s). No funds were received in support of this work. No benefits in any form have been or will be received from a commercial party related directly or indirectly to the subject of this manu- script. Our study was approved by the Institutional Review Board of Hitachi General Hospital. The authors report no conflicts of interest.

Corresponding Author: Kosei Nagata, MD, Department of Orthopaedic Surgery and Spinal Surgery, The University of Tokyo Hospital, 7-3-1 Hongo, Bunkyo-ku, Tokyo, 113-8655, Japan. Phone: +81-3-3815-5411; Fax: +81-3-3818-4082; Email: knagata-tky@umin.ac.jp.

Published 22 January 2021

This manuscript is generously published free of charge by ISASS, the International Society for the Advancement of Spine Surgery. Copyright (c) 2020 ISASS. To see more or order reprints or permissions, see http://ijssurgery.com. 